"smoothly run exercise causing minimal distress", not least for the organising team.

\section{Acknowledgement}

Dr T. El-Gohary who first devised the timetable.

\section{Reference}

ARMstrong, D. \& LOOSEMORE, S. (1988) How to plan the MRCPsych Part II examination: organising the clinical examination without affecting your mental health. Bulletin of the Royal College of Psychiatrists, 12, 229-230.

\title{
Quality thinking and a formula they can't refuse ${ }^{1}$
}

\author{
Nick ChILD, Consultant Child and Adolescent Psychiatrist, Child and Family Clinic, \\ 41 Airbles Road, Motherwell ML1 2TJ
}

In the peripheries of excellence, ${ }^{2}$ providing a service is the main task. Professor Nichol says that describing a child psychiatry service to managers is easy (Third Section Newsletter). I say it is and it is not. The way he does it follows the traditional bioscientific medical pattern and logic-number and range of cases and diagnoses etc. Health managers at a first glance may be quite happy with this 'biomedical'looking picture. But I believe that in their second glance they can tell that these expensive child psychiatrists, who just sit in rooms talking, are not dealing with the same thing as surgeons and physicians.

The manager's suspicious subliminal logic may go: "If the 7,500 (or whatever) children with psychiatric disorder in a district population are in the same category as biomedical problems like fractures and infections, there would be a lot more public fuss if nine out of ten cases were not even seeing, let alone being cured by, a child psychiatrist. And they say the disorders are multifactorial, so they can just as well be dealt with by other (less expensive) health professionals or - even better - another agency or authority altogether. We have certainly not got funds for ten times the number of child psychiatrists. In fact, if nothing serious happens to the nine out of ten kids who do not see a child psychiatrist, perhaps the one in ten does not need one either. Perhaps we do not really need any child psychiatry service."

Thus the easy medical-style could cook our goose. Of course, there is no rule that says doctors must only help people with biomedical conditions. But that is the rule our medical empire has pushed strongly into place. And child psychiatrists are the worst, without endless futile ${ }^{3}$ multi-axial attempts to label everything that moves as part of International Classifications of Diseases! Yet in our clinics and research, we know that the final loading of the dice that throws up psychiatric disorder is not "biomedical" but to do with "predicaments" and personal relationships, especially those in the family." However, because someone may think a biomedical physical or mental illness may be the explanation, there is still an essential place for a doctor's authority in diagnosing 'health' or the limits of any 'disease' present. Only a doctor has the skill to contribute authoritatively in this issue. ${ }^{5}$ This notional position (of diagnosing 'health') would be nothing special if it was not accompanied by offering skilled help to work out what else the problem could be, and be helped by and this should not then be called something vaguely medical and mystifying like such-and-such a 'therapy'.

Explaining all this complexity can begin with the usual data, thus:

"There are an estimated 7,500 children and adolescents per 200,000 population disturbed enough to fit an objective definition of psychiatric disorder. Psychiatric disorder is well known to be multi-factorially produced, but the key factor is equally well known to be family factors and functioning. Directly involved with worrying and responsibilities for these 7,500 children will be their families (nuclear, extended and substitute). That is another 20,000 close family members involved in these cases. It is also well-known that other members of such families have a high proportion of related physical, mental and social disorder and will be attending relevant helping professions in their own right.

It follows from all this that child and adolescent psychiatric disorder must be considered within a (demystified) family-systems approach, not just isolated as a disorder within the individual child".

Next, brief case descriptions can show how serious and distressing these 'predicaments' can be, even though they are not usually biomedical or lifethreatening situations. We emphasise how people can anyway be high users of medical services in various ways, just because they are desperate, or sure the 
problem is medical. Indeed, it shows how relatively distressing these problems can be that so many bring them to doctors because they would actually prefer that they were biomedical! We continue:

"How can a miniscule service like ours begin to tackle this mountain of children and families? We could just start burrowing blindly into the mountain and create a few hundred molehills a year. This might look as good in our monthly statistics as a surgeon's or GP's work does. But even an unintelligent manager [and remember this is being read by a manager] would soon ask whether this is tackling the mountain of providing a comprehensive service to the defined population. Like the intelligent manager, child and family clinics' practice, in general and with each case, must be based on continuous quality thinking. Quality thinking is, of course, closely followed by quality communicating and planning."

We go on to outline all the levels of our job that require quality thinking, communicating and planning. We emphasise how different this is (and looks) to the usual relatively automatic concrete procedures of other branches of medicine. ${ }^{6}$ We point out how easy it should be for managers to understand us since they too spend their time-all their time-thinking, communicating and planning. They do not see any patients.

Our quality solution to the question of overall strategy is to count ourselves as an essential member of a team of agencies and professionals that serve the district's mountain of multifactorial cases - with all that's implied when you take the word "team" seriously. ${ }^{7}$

But what formula can the least interested manager not refuse? In line with the logic above, my formula condenses into the following attention-gaining double-bind:

"So since a manager sees no patients at all, does that mean he is completely useless and dispensable?"

\section{Notes}

(1) This paper was originally presented in the 'How I Do It (in eight minutes!)' section of the 1990 Annual Residen- tial Conference of the Child and Adolescent Specialist Section of the Royal College of Psychiatrists, held in Glasgow.

(2) I would deny that this paper shows me to be antiestablishmentarian. I am forever grateful to those colleagues who drain themselves into the 'centres' professional bodies, universities, large and/or teaching hospitals, in-patient units, mainline training and teaching, other courses, writing text-books, doing research etc. Without the 'centres', there could be no 'peripheries' of excellence.

(3) 'Futile' from the point of view of service provision where a simple diagnostic category or label only rarely has the same useful power as diagnoses in biomedical fields. One good result of the present government's policy is to remind us that quality service provision is actually the primary aim supposed to be served by all those other 'central' enterprises that often take priority over service considerations.

(4) I draw from D. C. Taylor's ideas. For references see my letter, 'The Myth of Hysteria as Illness' (Journal, December 1989, 155, 865-866). Unlike 'diseases', 'predicaments' are unique, which is why further classification is less useful clinically. But we can still seek better frameworks for classification - 'problemsolving styles' perhaps?

(5) This medical authority does not often have to contribute explicitly within a multidisciplinary team. When anything explicit is needed, it is usually only good history taking and discussion. If any further biomedical attention is indicated - usually referrals will have already had quite enough - the case can be referred back to 'proper' medics.

(6) An added bonus of this way of thinking is that you get on far better with colleagues in the biomedical branches of medicine because you confirm what they have always known - that you are working with people and problems that are not in the same realm as biomedical disease. It is more likely that non-medical professionals and agencies occasionally dislike this way of thinking for, like the families themselves, they may wish for an unduly mystical power to hand over to.

(7) Our 'quality thinking' here is diametrically opposed to the present government's. The idea of inter-agency collaboration (although widely considered essential) is incompatible with creating a competitive market-place. May the best thinking win! 